\title{
Endoscopic management of bleeding gastrointestinal tumors
}

\author{
Andrew Ofosua, Daryl Ramai ${ }^{b}$, Will Latsona, Douglas G. Adlerc
}

The Brooklyn Hospital Center, NY; University of Utah School of Medicine, Huntsman Cancer Center, Salt Lake City, USA

Abstract

Bleeding due to primary or metastatic gastrointestinal (GI) tumors remains clinically challenging. Bleeding is further complicated in the setting of underlying friable neovascularization of tumors and coagulopathy. Endoscopic hemostatic therapeutic options have traditionally involved the use of thermal/mechanical therapy in conjunction with injection therapy. This review looks at the role of endoscopy in managing tumor-related GI bleeding, specifically contact and non-contact thermal therapy, radiofrequency ablation, endoloops, epinephrine and ethanol injection, and, most recently, Hemospray. Overall, current data show that endoscopic therapy is limited, with high rebleeding rates and a failure to improve overall outcomes. Larger clinical trials are needed to determine the efficacy of current techniques and establish therapeutic algorithms, with the goal of achieving primary hemostasis and reducing rebleeding rates.

Keywords Endoscopic therapy, gastrointestinal tumor bleed, argon plasma coagulation, radiofrequency ablation, injection, endoloop, Hemospray

Ann Gastroenterol 2019; 32 (4): 1-6

\section{Introduction}

Gastrointestinal (GI)-related tumor bleeding occurs in the setting of primary GI tumors, metastatic disease to the GI tract or a locally invasive tumor [1,2]. GI-related tumor bleeding accounts for $12-15 \%$ of cases of acute GI hemorrhage $[3,4]$. About $3-11 \%$ of acute lower GI bleeding is related to colonic neoplasms [5] (Fig. 1). In contrast, tumor bleeding accounts for $1-5 \%$ of upper GI bleeding, mainly related to gastric cancer [6,7] (Fig. 2). The clinical presentation of GI-related tumor bleeding varies from obscure GI bleeding to severe bleeding and may represent the initial manifestation of malignant disease [8] (Fig. 3).

The role of conventional endoscopic therapy with the use of thermal/mechanical therapy in conjunction with injection therapy in the management of non-variceal GI

${ }^{a}$ Division of Gastroenterology and Hepatology, The Brooklyn Hospital Center, NY (Andrew Ofosu, Will Latson); 'bepartment of Medicine, The Brooklyn Hospital Center, NY (Daryl Ramai); cDivision of Gastroenterology and Hepatology, University of Utah School of Medicine, Huntsman Cancer Center, Salt Lake City, Utah (Douglas G. Adler), USA

\section{Conflict of Interest: None}

Correspondence to: Douglas G. Adler MD, FACG, AGAF, FASGE, Division of Gastroenterology and Hepatology, University of Utah School of Medicine, Huntsman Cancer Center, Salt Lake City, Utah, USA, e-mail: Douglas.adler@hsc.utah.edu

Received 21 February 2019; accepted 1 April 2019; published online 31 May 2019

DOI: https://doi.org/10.20524/aog.2019.0391 bleeding has been shown to improve outcomes [9]. Despite favorable endoscopic outcomes in non-variceal GI bleeding, endoscopic hemostasis related to GI tumor bleeding has not appeared promising. Limited data show that the effectiveness of conventional endoscopic therapy is variable, with initial hemostasis achieved in $31-40 \%$ of patients, a short-term rebleeding rate of about $80 \%$, and 90 -day mortality of about $95 \%[10,11]$.

In contrast to benign related GI bleeding in which coaptive coagulation and ligation of bleeding vessels are achieved with thermal coagulation and mechanical therapy, respectively, management of GI-related tumor bleeding is endoscopically challenging. A myriad of underlying factors, such as local vessel invasion, friable neovascularization of tumors and underlying coagulopathy including thrombocytopenia, render endoscopic hemostasis in some instances unsuccessful, resulting in high recurrent bleeding rates $[7,12]$.

In this review, we discuss the currently available endoscopic therapeutic modalities used in the management of GI-related tumor bleeding.

\section{Thermal therapy}

Thermal devices used in the treatment of GI bleeding include a variety of contact and noncontact modalities. Current contact thermal devices include heater probes, multipolar electrocautery probes, the mono-polar probe and coagulation forceps (Coagrasper; Olympus Corp., Tokyo, Japan). Noncontact thermal techniques include the use of argon plasma coagulation (APC) and laser coagulation. 


\section{Contact thermal therapy}

The use of thermal therapy, with and without other endoscopic modalities, specifically for GI tumor bleeding has been demonstrated in several small case series. Savides et al, in a retrospective analysis, evaluated clinical outcomes from the use of thermal therapy with the use of a heater probe or bipolar electrocautery, with or without adjunctive epinephrine, in patients with upper GI-related tumor bleeding. Their study included 42 patients with GI-related tumor bleeding (6 with esophageal cancer, 10 with small-bowel tumors, and 26 with gastric malignancies). Only 7 patients had lesions requiring endoscopic therapy.

Initial hemostasis was successfully achieved in all 7 patients treated endoscopically. Despite initial successful hemostasis, the study revealed a 30-day rebleeding rate similar to the non-endoscopically treated patients (33\% vs. 29\%), with 30 -day mortality higher in the endoscopically treated group vs. the non-endoscopically treated group, possibly because they were more acutely ill [13]. The authors concluded that the use of thermal therapy, with or without adjunctive epinephrine, in GI-related tumor bleeding was initially effective and may provide time for more definitive tumor therapy.

Likewise, Loftus et al retrospectively reviewed the endoscopic management of patients with acute GI bleeding from upper GI malignant tumors. Their study analyzed the outcomes of 15 patients with bleeding advanced upper GI tumors requiring endoscopic therapy. Among a total of 28 endoscopic sessions, a heater probe was used as monotherapy in 8 sessions and as combination therapy with epinephrine in 10 sessions. Other endoscopic modalities used included Nd:YAG laser and epinephrine. Initial endoscopic hemostasis was achieved in $67 \%$ ( 10 of the 15 patients); however, the 30 day rebleeding rate was $80 \%$ in patients with initially achieved endoscopic hemostasis (8 of the 10 patients) [14]. Both studies reveal high rebleeding rates after the use of contact thermal therapy for GI-related tumor bleeding, despite initial successful hemostasis.

\section{Non-contact thermal therapy}

APC uses ionized argon gas to deliver thermal energy to tissues. Ionized argon gas travels from the tip of an endoscopic probe to tissue, causing local tissue necrosis and coagulation to a depth of roughly 2-3 $\mathrm{mm}$ if applied properly, but can cause deeper tissue injury (Fig. 4).

APC is a safe, simple, and cost-effective method for managing GI bleeding [15-19]. Akhtar et al reported using APC for the management of gastric tumor bleeding in 5 patients [20]. Three patients achieved successful hemostasis. Complete and partial hemostasis rates were $60 \%$ and $40 \%$, respectively, using relatively high power settings ( $70 \mathrm{~W}, 2.0 \mathrm{~L} / \mathrm{min}$ gas flow).

Thosani et al also reported a retrospective study involving 10 patients with upper (80\%) and lower (20\%) GI tumor bleeding [21]. Hemostasis was achieved in $100 \%$ of patients using only APC in 8 patients and with adjuvant epinephrine in

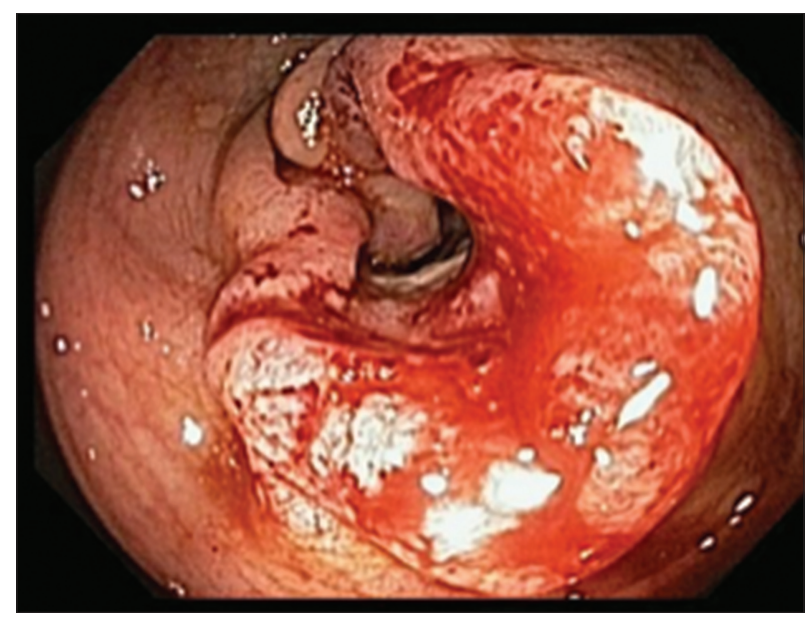

Figure 1 Endoscopic image of a colon cancer with chronic spontaneous bleeding

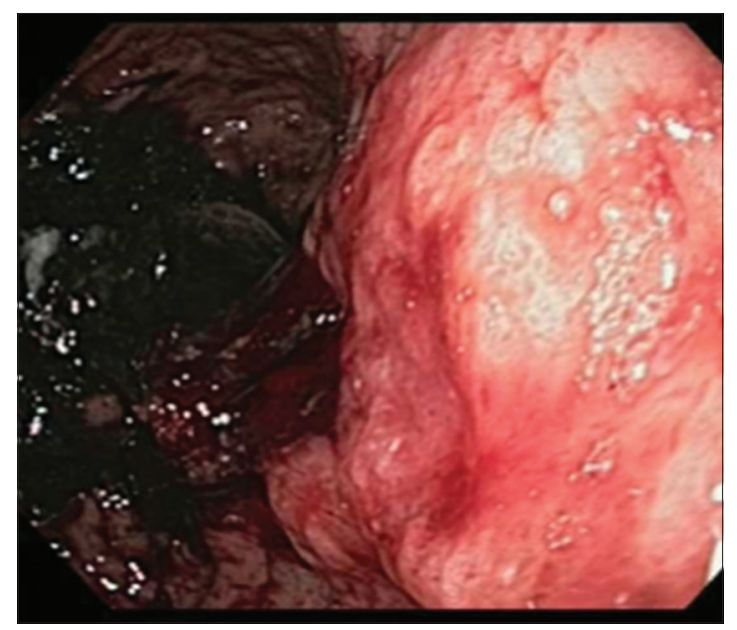

Figure 2 Endoscopic image of a briskly bleeding gastric cancer

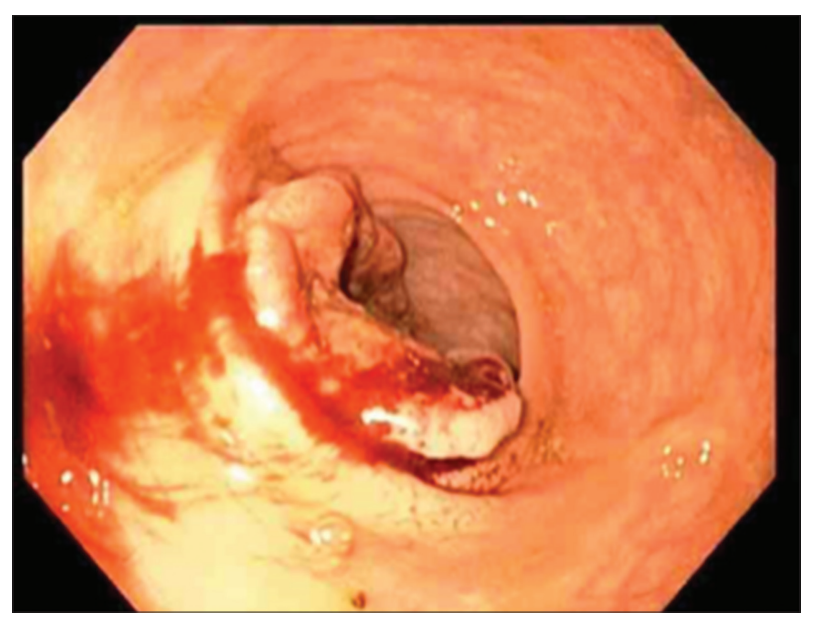

Figure 3 Endoscopic image of a rectal cancer diagnosed after the patient presented with hematochezia

the other 2. Rebleeding occurred in 3 patients. Likewise, Martins et al compared 25 patients with upper GI tumor bleeding who 
underwent APC with 28 patients who did not [21]. The study reported no differences in 30-day rebleeding (33.3\% in the APC group vs. $14.3 \%$ in the control group; $\mathrm{P}=0.104$ ) [22] (Table 1).

APC appears to achieve initial hemostasis in most cases [22]. However, this appears to be temporary given the high rebleeding rates. In our experience, the potential advantages of APC include ease of application, rapid and wide treatment of multiple lesions related to tumor bleeding, and reduced depth of penetration, limiting the risk of perforation. Current data on the use of APC in GI-related tumor bleeding are limited to these small retrospective studies. Larger studies are needed to objectively examine the protective effect of APC and rebleeding rates stratified according to upper and lower GI tumors.

\section{Radiofrequency ablation (RFA)}

RFA has been employed to manage a variety of GI lesions endoscopically. RFA has been shown to be a promising approach in treating cystic pancreatic neoplasms and Barrett's esophagus [23,24]. Little is known about the clinical and technical success of RFA in managing GI tumor related bleeding.

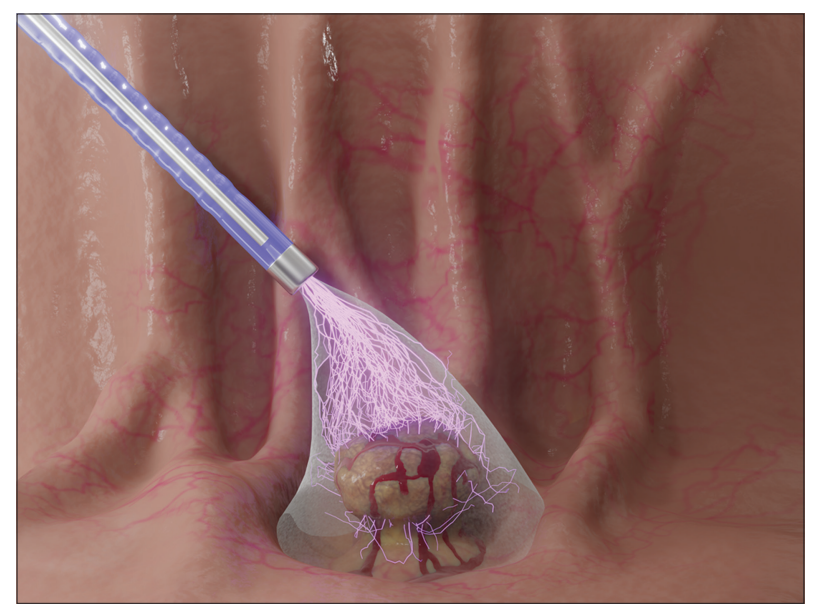

Figure 4 Illustration of endoscopic argon plasma coagulation being used to treat a bleeding gastrointestinal tumor
One report by Vavra et al demonstrated that radiofrequency energy can be safely and directly delivered into rectal cancers by inserting a specialized RFA probe (Habib Endoblate ${ }^{\mathrm{Tm}}$ ) 2-3 $\mathrm{mm}$ into the mass, during either flexible endoscopy or transanal endoscopic microsurgery [25]. In this pilot study of 12 patients with rectosigmoid tumors, 10 patients were treated with RFA followed by tumor resection. This cohort reported $82 \%$ (on average) destruction of tumor mass and complications at surgery. RFA alone was used in the remaining 2 patients to stop tumor bleeding. No other reports exist to support the use of RFA in treating bleeding GI tumors. Consequently, RFA remains experimental for this indication at this time.

\section{Endoloops}

Disposable snares, also known as endoloops, are used primarily as prophylaxis for post-resection bleeding. This technique has been used in the same context for a number of gastric defects, including lipomas, angiodysplasia, and sessile ulcerated tumors [26,27].

If the tumor stalk is large, it is more likely to contain a large artery, complicating hemostasis [28]. Mubarak et al described the difficulty of achieving hemostasis in a large solitary fibrous tumor of the esophagus. The size of the stalk led to slippage of the endoloop after tumor resection and subsequent hemorrhage, managed via thermal coagulation [29].

Kashani et al described a patient with a periampullary tumor resultant of metastatic hepatocellular carcinoma managed by 2 endoloops placed 1 month apart, resulting in stabilization of hemoglobin levels [30]. Brkic described preoperative management of what was revealed to be a GI stromal tumor with active bleeding from an ulcerated crater in the gastric fundus [31]. An endoloop was placed around the base of the tumor and the top of the ulcerated lesion protruded. After the endoloop was tightened, no clinical recurrence of bleeding was detected. Shortly thereafter, the patient underwent elective wedge tumor resection.

Overall, the use of an endoloop to manage active tumor bleeding is promising; however, the difficulty of proper placement increases with tumor size, as does the ability to control bleeding from larger arteries.

Table 1 Studies evaluating the use of argon plasma coagulation (APC) for managing tumor-related gastrointestinal bleeding

\begin{tabular}{|c|c|c|c|c|c|c|c|}
\hline Study & Year & Patients & Site of lesion & Procedure & APC settings & $\begin{array}{c}\text { Initial } \\
\text { Hemostasis }\end{array}$ & Rebleeding \\
\hline $\begin{array}{l}\text { Akhtar } \\
\text { et al }[20]\end{array}$ & 2000 & 3 & Upper (100\%) & APC (100\%) & $\begin{array}{l}70 \mathrm{~W}, 2.0 \mathrm{~L} / \mathrm{min} \\
\text { (All lesions) }\end{array}$ & $\begin{array}{c}60 \% \\
\text { Complete } \\
40 \% \text { Partial }\end{array}$ & Unknown \\
\hline $\begin{array}{l}\text { Thosani } \\
\text { et al [21] }\end{array}$ & 2014 & 10 & $\begin{array}{l}\text { Upper }(80 \%) \\
\text { Lower }(20 \%)\end{array}$ & $\begin{array}{l}\text { APC (80\%) } \\
\text { APC+Epinephrine (20\%) }\end{array}$ & $\begin{array}{l}35 \mathrm{~W}, 1.0 \mathrm{~L} / \mathrm{min} \\
\text { (All lesions) }\end{array}$ & $100 \%$ & $33 \%$ \\
\hline $\begin{array}{l}\text { Martins } \\
\text { et al [22] }\end{array}$ & 2016 & 25 & Upper (100\%) & $\operatorname{APC}(100 \%)$ & $\begin{array}{l}60-70 \mathrm{~W}, 1.5-2.0 \mathrm{~L} / \mathrm{min} \\
\text { (esophageal/gastric lesions) } \\
40-50 \mathrm{~W}, 1.5 \mathrm{~L} / \\
\text { min (duodenal lesions) }\end{array}$ & $73.30 \%$ & $33.30 \%$ \\
\hline
\end{tabular}




\section{Injection therapy}

\section{Epinephrine}

The use of hypertonic saline epinephrine solution (HSE) was first described by Hirao et al in the prophylaxis of post-resection bleeding following endoscopic removal of gastric cancer [32]. Its proposed mechanism of action involves local vasoconstriction and vascular tamponade, along with edema and fibrinoid degeneration of the arterial wall leading to thrombogenesis [33]. Since then, it has developed as a useful adjunct for pre- and post-procedural hemostatic management of GI tumor bleeding. This achieves transient hemostasis with minimal tissue damage, allowing the preservation of postprocedural biopsy tissue. Though tissue damage is minimal, HSE can induce a locally thrombogenic state, compounding its effectiveness [32]. It is typically injected using a 4-quadrant technique in $0.5-2 \mathrm{~mL}$ aliquots of a 1:10,000 dilution of epinephrine in physiological saline [33].

Kanai described a case series of 254 patients with varying degrees of active bleeding. Eight patients presented with active gastric tumor bleeding in which HSE was used in conjunction with APC to achieve permanent hemostasis. As the study design focused on the use of APC, it was difficult to determine the outcomes of HSE as monotherapy. However, of the 254 patients, initial hemostasis was achieved with HSE and/or clipping (99.6\%) [18]. Overall, injection with HSE appears to be an effective method of achieving hemostasis in bleeding GI tumors, though it is mostly used as adjunctive therapy.

\section{Ethanol}

Absolute ethanol injection therapy for GI bleeding was first developed by Asaki and is based on the dehydration and fixation of tissue resulting in necrosis of the endothelial wall, thus facilitating thrombogenesis [34]. In a later clinical trial, the same group documented its use in the management of post-procedural bleeding, including patients with bleeding from tumors. Of 51 patients, 5 had active bleeds from tumors, all of which were initially managed via local ethanol injection. Long-term outcomes from tumor bleeds as a separate group were not reported, but rebleeding rates in the study as a whole were low (3\%) [34]. Complications limit the widespread use of ethanol injection and only small amounts are recommended, as high concentrations have been shown to increase the risk of perforation [35].

Given the questions about its efficacy and safety, injection monotherapy overall has been largely supplanted by more modern techniques such as band ligation, looping, and electrocautery techniques [33]. Recent use of ethanol injection in GI tumor bleeding management involves direct ethanol injection for ablative therapy using endoscopic ultrasound assisted guidance. This has been reported with positive clinical success for gastrointestinal stromal tumors with no bleeding complications [36,37]. It should be noted that there have been no clinical trials of this technique and evidence is limited to case reports.

\section{Hemospray}

Hemospray (Cook Endoscopy, Winston-Salem NC) is a hemostatic powder recently approved in the United States for endoscopic hemostasis in non-variceal GI bleeding [38]. The device uses a gas canister to deliver the powder through a catheter to an endoscopic target. Tumor-associated GI bleeding tends to be diffuse, often lacking a clear target for limiting control with conventional endoscopic therapy using thermal and mechanical modalities. Hemospray is theoretically well suited for GI bleeding because it does not require contact and can be rapidly applied without requiring an en face view of the lesion.

Leblanc et al conducted a study to determine the effectiveness of the use of Hemospray in achieving hemostasis in patients with bleeding related to GI malignancies [39]. In their study, 5 patients in the malignancy group had active upper GI bleeding due to malignancies of the esophagus, stomach or pancreas. Hemospray was used as first-line monotherapy in 4 of the 5 patients $(80.0 \%)$, with immediate hemostasis achieved in these 4 patients. One patient who continued to bleed despite placement of hemostatic clips achieved immediate hemostasis after Hemospray was applied as rescue therapy. Follow up at day 7 reported 2 patients who developed rebleeding subsequently treated using Hemospray as monotherapy during endoscopy. Immediate hemostasis was achieved in all patients, though one patient had another recurrence within 30 days. No procedurerelated adverse events were noted.

Pittayanon et al conducted a study to compare the efficacy of Hemospray and conventional endoscopic hemostasis in GI-related tumor bleeding [40]. Ten patients who received Hemospray as first-line hemostatic therapy were matched with 10 historical controls based on the type of GI tumors. On day 14 , the rebleeding rate in the control group was 3 times that in the Hemospray group, though the difference was not statistically significant ( $30 \%$ vs. $10 \% ; \mathrm{P}=0.60)$. In the Hemospray group, nine of the 10 patients required no further endoscopic therapy during the first 2 weeks after initial therapy, whereas in the historical control group $3 / 10$ patients (30\%) re-bled and required rescue intervention. Additionally, the control group reported three times higher mortality compared to the Hemospray group, though again the difference was not statistically significant ( $30 \%$ vs. $10 \% ; \mathrm{P}=0.7)$. Length of stay did not differ significantly between the 2 groups of patients $(28.2 \pm 21.2$ vs. $23.8 \pm 12.5$ days; $\mathrm{P}=0.26)$.

Arena et al, in 2017, conducted a retrospective study on the safety and efficacy of Hemospray as sole therapeutic modality in achieving hemostasis in GI-related tumor bleeding [41]. Their study included 15 patients with upper GI-related tumor bleeding. Among the 15 patients, immediate hemostasis was achieved in 14 patients (93.3\%) after application of Hemospray during endoscopy. Three patients, among those successfully treated, re-bled, 2 within 3 days, and were successfully retreated with Hemospray with adjunctive thermal and injection therapy. However on 6-day follow up, these 2 patients succumbed to rebleeding and multi-organ failure.

Despite the benefits of Hemospray, there are also safety issues. There is a potential risk of obscuring the target lesions 
after failed application of Hemospray, making it challenging to apply other hemostatic options [42]. Furthermore, there is a risk of catheter occlusion if the delivery device comes into contact with blood.

The use of Hemospray in managing GI tumor bleeding is promising but has not been sufficiently studied to allow global conclusions regarding its efficacy [43-48]. Further studies with large sample sizes, in addition to costeffectiveness analyses, are needed to clearly define the role of Hemospray as a standalone therapy in the management of GI-related bleeding.

\section{Non-endoscopic therapy}

Endoscopic therapy appears to be a cost-effective and safe means for managing GI tumor bleeds but is associated with high rebleeding rates [7,49]. National guidelines acknowledge the shortcomings of endoscopic therapy, but note that endoscopic treatment may avert urgent surgery, reduce transfusion requirements, and may provide a temporary bridge to oncologic therapy and/or selective embolization [50].

Surgery and interventional radiology remain the 2 most effective approaches and should be considered when endoscopic therapy fails [6]. Surgical intervention may include vessel ligation or resection, while radiological procedures may involve the use of percutaneous transcatheter arterial embolization with a variety of mechanical devices or sclerosing agents [51]. Though effective for treating GI tumor bleeds, cost, mortality, and life expectancy should be carefully weighed.

\section{Concluding remarks}

The endoscopic management of GI tumor-related bleeding is challenging because of high rebleeding rates, poor tissue response to endoscopic therapies, altered wound healing, and failure to improve the overall outcome of disease. Rebleeding rates with endoscopic therapies remain high despite aggressive intervention. Cases that fail endoscopic therapy, or are not indicated for endoscopy, may require surgical or radiological intervention. However, given the poor success rates and the lack of large studies to critically evaluate current endoscopic modalities, it remains unclear whether endoscopy will improve outcomes in patients with GI tumor bleeds. New endoscopic technologies for endoscopic hemostasis are needed, which will have the potential to improve outcomes in patients with tumor bleeding when conventional modalities fail. Moreover, endoscopic therapies also have the potential of being cost-effective and safer than surgical alternatives. Large clinical trials with long-term follow up are needed to determine which endoscopic modalities are best suited for controlling tumor bleeding and to develop better-adapted hemostatic guidelines.

\section{Acknowledgment}

We would like to thank Mr. Sahrin Samad for the medical illustration.

\section{References}

1. Imbesi JJ, Kurtz RC. A multidisciplinary approach to gastrointestinal bleeding in cancer patients. J Support Oncol 2005;3:101-110.

2. [No authors listed]. A phase II multicentre trial of endoscopic ultrasound guided radiofrequency ablation of cystic tumours of the pancreas (RADIOCYST01). ClinicalTrials.gov Identifier: NCT02343692.

3. Lightdale CJ, Kurtz RC, Boyle CC, Sherlock P, Winawer SJ. Cancer and upper gastrointestinal tract hemorrhage. Benign causes of bleeding demonstrated by endoscopy. JAMA 1973;226:139-141.

4. Shivshanker K, Chu DZ, Stroehlein JR, Nelson RS. Gastrointestinal hemorrhage in the cancer patient. Gastrointest Endosc 1983; 29:273-275.

5. Strate LL. Lower GI bleeding: epidemiology and diagnosis. Gastroenterol Clin North Am 2005;34:643-664.

6. Kim YI, Choi IJ. Endoscopic management of tumor bleeding from inoperable gastric cancer. Clin Endosc 2015;48:121-127.

7. Sheibani S, Kim JJ, Chen B, et al. Natural history of acute upper GI bleeding due to tumours: short-term success and long-term recurrence with or without endoscopic therapy. Aliment Pharmacol Ther 2013;38:144-150.

8. Schatz RA, Rockey DC. Gastrointestinal bleeding due to gastrointestinal tract malignancy: natural history, management, and outcomes. Dig Dis Sci 2017;62:491-501.

9. Sung JJ, Tsoi KK, Lai LH, Wu JC, Lau JY. Endoscopic clipping versus injection and thermo-coagulation in the treatment of nonvariceal upper gastrointestinal bleeding: a meta-analysis. Gut 2007; 56:1364-1373.

10. Adler DG, Leighton JA, Davila RE, et al; ASGE. ASGE guideline: The role of endoscopy in acute non-variceal upper-GI hemorrhage. Gastrointest Endosc 2004;60:497-504.

11. Roberts SE, Button LA, Williams JG. Prognosis following upper gastrointestinal bleeding. PLoS One 2012;7:e49507.

12. Heller SJ, Tokar JL, Nguyen MT, Haluszka O, Weinberg DS. Management of bleeding GI tumors. Gastrointest Endosc 2010; 72:817-824.

13. Savides TJ, Jensen DM, Cohen J, et al. Severe upper gastrointestinal tumor bleeding: endoscopic findings, treatment, and outcome. Endoscopy 1996;28:244-248.

14. Loftus EV, Alexander GL, Ahlquist DA, Balm RK. Endoscopic treatment of major bleeding from advanced gastroduodenal malignant lesions. Mayo Clin Proc 1994;69:736-740.

15. Herrera S, Bordas JM, Llach J, et al. The beneficial effects of argon plasma coagulation in the management of different types of gastric vascular ectasia lesions in patients admitted for GI hemorrhage. Gastrointest Endosc 2008;68:440-446.

16. Pavey DA, Craig PI. Endoscopic therapy for upper-GI vascular ectasias. Gastrointest Endosc 2004;59:233-238.

17. Manner H. Argon plasma coagulation therapy. Curr Opin Gastroenterol 2008;24:612-616.

18. Kanai M, Hamada A, Endo Y, et al. Efficacy of argon plasma coagulation in nonvariceal upper gastrointestinal bleeding. Endoscopy 2004;36:1085-1088.

19. Canard JM, Védrenne B. Clinical application of argon plasma coagulation in gastrointestinal endoscopy: has the time come to replace the laser? Endoscopy 2001;33:353-357. 
20. Akhtar K, Byrne JP, Bancewicz J, Attwood SE. Argon beam plasma coagulation in the management of cancers of the esophagus and stomach. Surg Endosc 2000;14:1127-1130.

21. Thosani N, Rao B, Ghouri Y, et al. Role of argon plasma coagulation in management of bleeding GI tumors: evaluating outcomes and survival. Turk J Gastroenterol 2014;25(Suppl 1):38-42.

22. Martins BC, Wodak S, Gusmon CC, et al. Argon plasma coagulation for the endoscopic treatment of gastrointestinal tumor bleeding: A retrospective comparison with a non-treated historical cohort. United European Gastroenterol J 2016;4:49-54.

23. Ofosu A, Ramai D, Adler DG. Endoscopic ultrasound-guided ablation of pancreatic cystic neoplasms: ready for prime time? Ann Gastroenterol 2019;32:39-45.

24. Phoa KN, van Vilsteren FG, Weusten BL, et al. Radiofrequency ablation vs endoscopic surveillance for patients with Barrett esophagus and low-grade dysplasia: a randomized clinical trial. JAMA 2014;311:1209-1217.

25. Vavra P, Dostalik J, Zacharoulis D, Khorsandi SE, Khan SA, Habib NA. Endoscopic radiofrequency ablation in colorectal cancer: initial clinical results of a new bipolar radiofrequency ablation device. Dis Colon Rectum 2009;52:355-358.

26. Aydin HN, Bertin P, Singh K, Arregui M. Safe techniques for endoscopic resection of gastrointestinal lipomas. Surg Laparosc Endosc Percutan Tech 2011;21:218-222.

27. Arezzo A, Verra M, Miegge A, Morino M. Loop-and-let-go technique for a bleeding, large sessile gastric gastrointestinal stromal tumor (GIST). Endoscopy 2011;43 Suppl 2 UCTN: E18-E19.

28. Paspatis GA, Paraskeva K, Theodoropoulou A, et al. A prospective, randomized comparison of adrenaline injection in combination with detachable snare versus adrenaline injection alone in the prevention of postpolypectomy bleeding in large colonic polyps. Am J Gastroenterol 2006;101:2805; quiz 2913.

29. Mubarak MF, Shah JN, Bolton JS, Bansal M, El Chafic AH. Endoscopic resection of a giant solitary fibrous tumor of the esophagus. VideoGIE 2018;3:343-345.

30. Kashani A, Nissen NN, Guindi M, Jamil LH. Metastatic periampullary tumor from hepatocellular carcinoma presenting as gastrointestinal bleeding. Case Rep Gastrointest Med 2015; 2015:732140.

31. Brkic T, Kalauz M, Ivekovic H. Endoscopic hemostasis using endoloop for bleeding gastric stromal tumor. Clin Gastroenterol Hepatol 2009;7:e53-e54.

32. Goker H, Haznedaroglu IC, Ercetin S, et al. Haemostatic actions of the folkloric medicinal plant extract Ankaferd Blood Stopper. J Int Med Res 2008;36:163-170.

33. Beyazit Y, Onder FO, Torun S, et al. Topical application of ankaferd hemostat in a patient with gastroduodenal amyloidosis complicated with gastrointestinal bleeding. Blood Coagul Fibrinolysis 2013;24:762-765.

34. Chen YI, Barkun AN. Hemostatic powders in gastrointestinal bleeding: a systematic review. Gastrointest Endosc Clin N Am 2015; 25:535-552.

35. Hirao M, Masuda K, Asanuma T, et al. Endoscopic resection of early gastric cancer and other tumors with local injection of hypertonic saline-epinephrine. Gastrointest Endosc 1988;34:264-269.

36. Fujishiro $M$, Iguchi $M$, Kakushima $N$, et al. Guidelines for endoscopic management of non-variceal upper gastrointestinal bleeding. Dig Endosc 2016;28:363-378.

37. Asaki S, Nishimura T, Satoh A, et al. Endoscopic hemostasis of gastrointestinal hemorrhage by local application of absolute ethanol: a clinical study. Tohoku J Exp Med 1983;141:373-383.

38. Savides TJ, Jensen DM. Therapeutic endoscopy for nonvariceal gastrointestinal bleeding. Gastroenterol Clin North Am 2000; 29:465-487, vii.

39. Günter E, Lingenfelser T, Eitelbach F, Müller H, Ell C. EUS-guided ethanol injection for treatment of a GI stromal tumor. Gastrointest Endosc 2003;57:113-115.

40. Hernández-Ludeña L, Consiglieri CF, Gornals JB. EUS-guided ethanol ablation therapy for gastric stromal tumors. Rev Esp Enferm Dig 2018;110:69-70.

41. Seewald S, Sriram PV, Naga M, et al. Cyanoacrylate glue in gastric variceal bleeding. Endoscopy 2002;34:926-932.

42. Bhat YM, Banerjee S, Barth BA, et al; ASGE Technology Committee. Tissue adhesives: cyanoacrylate glue and fibrin sealant. Gastrointest Endosc 2013;78:209-215.

43. Prachayakul V, Aswakul P, Kachinthorn U. Spraying N-butyl-2cyanoacrylate (Histoacryl) as a rescue therapy for gastrointestinal malignant tumor bleeding after failed conventional therapy. Endoscopy 2011;43 Suppl 2 UCTN: E227-E228.

44. Suga H, Nakagawa T, Soga Y, et al. Endoscopic hemostasis using fibrin adhesive to treat hemorrhage in the upper digestive system. Surg Today 2004;34:902-906.

45. FDA News Release. FDA permits marketing of new endoscopic device for treating gastrointestinal bleeding. U.S. Food \& Drug Administration 2018. Available from: https://www.fda.gov/ NewsEvents/Newsroom/PressAnnouncements/ucm606799.htm [Accessed 17 April 2019].

46. Leblanc S, Vienne A, Dhooge M, Coriat R, Chaussade S, Prat F. Early experience with a novel hemostatic powder used to treat upper GI bleeding related to malignancies or after therapeutic interventions (with videos). Gastrointest Endosc 2013;78:169-175.

47. Pittayanon R, Prueksapanich P, Rerknimitr R. The efficacy of Hemospray in patients with upper gastrointestinal bleeding from tumor. Endosc Int Open 2016;4:E933-E936.

48. Arena M, Masci E, Eusebi LH, et al. Hemospray for treatment of acute bleeding due to upper gastrointestinal tumours. Dig Liver Dis 2017;49:514-517.

49. Kim YI, Choi IJ, Cho SJ, et al. Outcome of endoscopic therapy for cancer bleeding in patients with unresectable gastric cancer. J Gastroenterol Hepatol 2013;28:1489-1495.

50. Karstensen JG, Ebigbo A, Aabakken L, et al. Nonvariceal upper gastrointestinal hemorrhage: European Society of Gastrointestinal Endoscopy (ESGE) Cascade Guideline. Endosc Int Open 2018;6:E1256-E1263.

51. Johnstone C, Rich SE. Bleeding in cancer patients and its treatment: a review. Ann Palliat Med 2018;7:265-273. 